Fixed Point Theory, 18(2017), No. 1, 27-36

http://www.math.ubbcluj.ro/ nodeacj/sfptcj.html

\title{
KRASNOSEL'SKII-TYPE FIXED-SET RESULTS UNDER WEAK TOPOLOGY CIRCUMSTANCES AND APPLICATIONS
}

\author{
AFIF BEN AMAR*, MOHAMED BOUMAIZA** AND SANA HADJ AMOR** \\ *Faculté des Sciences de Sfax \\ Rue Soukra 3038 Sfax, Tunisia \\ E-mail:afif.benamar@ipeis.rnu.tn \\ ** Institut Supérieure des Sciences et de Technologies de Hammam Sousse \\ Rue Lamin El Abbassi 4011 Hammam Sousse, Tunisia \\ E-mail:mohamed.boumaiza@essths.rnu.tn, sana.hadjamor@yahoo.fr
}

\begin{abstract}
In this paper, using the technique of measure of weak noncompacteness, we prove some fixed set results of Krasnosel'skii type for the sum of two multivalued operators in the setting of weak topology, without the assumption of the convexity of their common domain. Applications to the theory of self-similarity are also given.

Key Words and Phrases: Krasnosel'skii theorem, fixed set, weak topology, self-similarity theory. 2010 Mathematics Subject Classification:47H10, 47H09.
\end{abstract}

\section{REFERENCES}

[1] A., Ben Amar, Krasnoselskii type fixed point theorems for multivalued mapping with weakly sequentially closed graph, Ann. Univ. Ferrara, 58(2012), 1-10.

[2] A. Ben Amar, A. Jeribi, M. Mnif, On a generalization of the Schauder and Krasnosel'skii fixed point theorems on Dunford-Pettis space and applications, Math. Methods Appl. Sci., 28(2005), $1737-1756$.

[3] A. Ben Amar, A. Jeribi, M. Mnif, Some fixed point theorems and application to biological model, Numer. Funct. Anal. Optim., 29(2008), no. 1, 1-23.

[4] C.S. Barrosso, E.V., Teixeira, A topological and geometric approach to fixed points results for sum of operators and applications, Nonlinear Anal., 60(2005), 625-650.

[5] A. Ben Amar, T. Xiang, Critical type of Krasnoselskii fixed point theorem in weak topology circumstances, Submitted.

[6] F.S. De Blasi, On a property of the unit sphere in a Banach space, Bull. Math. Soc. Sci. Math. Roumanie, 21(1977), no. 69, 259-262.

[7] R.E. Edwards, Functional Analysis, Theory and Applications, Holt, Reinhart and Winston, 1965.

[8] J. Hutchinson, Fractals and self similarity, Indiana Univ. Math. J., 30(1981), 713-747.

[9] M.A. Krasnosel'skii, Some problems of nonlinear analysis, Math. Soc. Transl. Ser. 2, 10(1958), no. 2, 345-409.

[10] Y.C. Liu, Z.X. Li, Krasnosel'skii type fixed point theorems and applications, Proc. Amer. Math. Soc., 136(2008), 1213-1220.

[11] E.A. Ok, Fixed set theory for closed correspondences with applications to self similarity and games, Nonlinear Anal., 56(2004), no. 3, 309-330. 
[12] E.A. Ok, Fixed set theorems of Krasnosel'skii type, Proc. Amer. Math. Soc., 137(2009), no. 2, 511-518.

[13] D. O'Regan, Fixed point theory for weakly contractive maps with applications to operator inclusions in Banach spaces relative to the weak topology, Z. Anal. Anwendungen, 17(1998), 282-296.

[14] D. O'Regan, Fixed point theorems for weakly sequentially closed maps, Arch. Math., 36(2000), 61-70.

[15] M.A. Taoudi, Krasnoselskii type fixed point theorems under weak topology features, Nonlinear Anal., 72(2010), 478-482.

[16] M.A. Al-Thagafi, N. Shahzad, Krasnoselskii-type fixed point results, Fixed Point Theory and Applications, ID 394139 (2009), 9 pages.

[17] T. Xiang, R. Yuan, Critical type of Krasnosel'skii fixed point theorem, Proc. Amer. Math. Soc., 139(2011), 1033-1044.

[18] T. Xiang, R. Yuan, Krasnoselskii-type fixed point theorems under weak topology settings and applications, Electronic J. Diff. Equations, 35(2010), 1-15.

Received: February 26, 2014; Accepted: February 28, 2015. 